\title{
Neurological and neurourological complications of electrical injuries
}

\author{
Konstantina G. Yiannopoulou ${ }^{1}$, Georgios I. Papagiannis ${ }^{2,3}$, Athanasios I. Triantafyllou, ${ }^{2,3}$, \\ Panayiotis Koulouvaris ${ }^{3}$, Aikaterini I. Anastasiou ${ }^{4}$, Konstantinos Kontoangelos ${ }^{5}$, Ioannis P. Anastasiou ${ }^{6}$ \\ ${ }^{1}$ Neurological Department, Henry Dunant Hospital Centre, Athens, Greece \\ ${ }^{2}$ Orthopaedic Research and Education Centre "P.N. Soukakos", Biomechanics and Gait Analysis Laboratory "Sylvia Ioannou”, \\ "Attikon" University Hospital, Athens, Greece \\ ${ }^{3} 1$ st Department of Orthopaedic Surgery, Medical School, National and Kapodistrian University of Athens, Athens, Greece \\ ${ }^{4}$ Medical School of Athens, National and Kapodistrian University of Athens, Athens, Greece \\ ${ }^{5} 1$ st Department of Psychiatry, National and Kapodistrian University of Athens, Eginition Hospital, Athens, Greece \\ ${ }^{6} 1$ st Urology Department, Laiko Hospital, National and Kapodistrian University of Athens, Athens, Greece
}

\begin{abstract}
Electrical injury can affect any system and organ. Central nervous system (CNS) complications are especially well recognised, causing an increased risk of morbidity, while peripheral nervous system (PNS) complications, neurourological and cognitive and psychological abnormalities are less predictable after electrical injuries.

PubMed was searched for English language clinical observational, retrospective, review and case studies published in the last 30 years using the key words: electrical injury, electrocution, complications, sequelae, neurological, cognitive, psychological, urological, neuropsychological, neurourological, neurogenic, and bladder.

In this review, the broad spectrum of neurological, cognitive, psychological and neurourological consequences of electrical trauma are discussed, and clinical features characteristic of an underlying neurological, psychological or neurourological disorder are identified. The latest information about the most recently discovered forms of nervous system disorders secondary to electrical trauma, such as the presentation of neurological sequelae years after electrocution, in other words long-term sequelae, are presented. Unexpected central nervous system or muscular complications such as hydrocephalus, brain venous thrombosis, and amyotrophic lateral sclerosis are described. Common and uncommon neuropsychological syndromes after electrical trauma are defined. Neurourological sequelae secondary to spinal cord or brain trauma or as independent consequences of electrical shock are also highlighted.
\end{abstract}

Key words: electrical injury, neurological sequelae, neurourological complications

(Neurol Neurochir Pol 2021; 55 (1): 12-23)

\section{Introduction}

As our society has become more advanced, automated, and technical, the physical risks associated with progress also have increased. This statement holds particularly true in the case of electrical injury. In addition, lightning-induced electrical injury is a timeless traumatic incident.
Though only up to $5 \%$ and $27 \%$ of admissions to burns units in developed and developing countries respectively are due to electrical injuries, the consequences can be highly destructive [1].

Electrical trauma mainly affects young males, being most common in the workplace among industrial workers in particular (e.g. those repairing power lines, workers striking 
power lines with machinery) and is the fourth most important cause of traumatic occupational death $[1,2]$. However, it also occurs frequently in and around the home (e.g. when installing television antennas, dropping an electrical appliance into water, using an unsafe swimming pool) $[1,3]$. High-voltage $(\geq 1,000 \mathrm{~V})$ accidents occur more frequently (57.71\%) than low-voltage burns $(<1,000 \mathrm{~V})(42.29 \%)$ [2]. The fatality rate, a reflection of the severity of electrical incidents and of the accessibility of specialised burns centres, ranges from $2.35 \%$ to $26.7 \%$ [2].

The clinical sequelae of an electrocution can appear immediately or hours, days or even years later [4].

As regards neurological consequences, approximately $50 \%$ of patients suffering low-voltage injuries have some degree of neurological symptoms, compared to $67 \%$ after sustaining high-voltage injuries [5].

The central nervous system involvement after an electrical injury is crucial and is immediately addressed and dealt with. For those who survive, remaining or delayed neurological deficits affect severely their quality of life and their ability to work. Furthermore, the long-term neurological, cognitive, psychological and neurourological sequelae of an electrical injury can remain unrecognised and worsen. From this point of view, it is unsurprising that many electrically injured people are confronted with serious working difficulties afterwards [5]. In fact, they are less likely to be employed one year post-injury, even compared to survivors of fires [6].

Amputations (with rates of 10-68\% in electrically injured survivors) [2,6] neurological impairments (21\%) [5], and neuropsychological and behavioural impairments (59.2\% in the same survivors) [5] are considered the main complications that affect the ability to return to work [2].

This review aims to provide a systematic evaluation of reported neurological outcomes of electrical injury in physical neurology, in an attempt to gain a more comprehensive understanding of the multiple immediate or delayed, short- or long-term consequences secondary to low- or high-voltage electrical or lightning injuries affecting the whole spectrum of the parts and functions of the nervous system. Special attention is given to neurourological syndromes that have been somewhat neglected in the literature of electrical trauma. Psychological and cognitive consequences are not described; due to their extensive variability, high frequency and longstanding severity, they demand separate analysis.

\section{Pathogenesis and pathophysiology}

\section{Pathogenesis and pathophysiology of electrical injuries}

Three defining characteristics are common to both fatal and non-fatal electrical injuries:

1. Accidental contact of the affected individual with an electric current
2. Failure of the personal protection system or electrical policy, practice, procedure or of the electrical design or installation to comply with basic safety rules

3. Electrical, mechanical, kinetic, potential, thermal, light or radiation energy are transferred in some combination to the victim.

Exposure to supraphysiological circumstances results in accidental injury. At $50-$ to $60-\mathrm{Hz}$ commercial power frequencies, supraphysiological energy transmission from a power source to the exposed individual is necessary to induce electrocution [7].

Generated electricity that is used in residential and industrial settings is available as direct current (DC) or alternating current (AC). DC follows a pattern of a continuous flow of electrons in one direction, whereas $\mathrm{AC}$ features a pattern of continuous reversal of electrons (i.e. flowing forwards then backwards). Radiation is an additional method of transmitting electrical energy to the body (e.g. microwaves, X-rays) [5].

Regardless of the means of transmission, electricity enters a victim at an entrance point, travels a particular path, and leaves via an exit point. Entrance points can come into direct or indirect contact with the source of electricity and may or may not suffer burns as a result of the electrical current meeting the resistance of the skin. Hands and head are the usual entrance points.

Exit points allow the electricity an avenue to leave the body in search of a grounding source. Although the exit point is determined by the path of the electrical current, hands, feet and legs are almost always the exit points. The exit of the current from the body may be a violent event leading to extreme damage. In cases of AC contact, the terms 'entrance' and 'exit' points may be irrelevant because the electrical current is continuously flowing into and out of the individual through the same point [7].

The path of least resistance determines the electrical current's path through the human body as the current searches for a grounding source. Different tissues in the body have different levels of resistance, and electrical current preferentially follows the least resistant of them. Blood vessels and nerves have lower levels of resistance than bones and fat, so the current tends to travel along them when it overcomes the skin's resistance. This may be one reason for the high rates of neurological sequelae associated with electrical injuries.

If, however, the current is dense enough, it will flow through whatever is in its path en route to the ground (e.g. muscles, tendons, bones). Common pathways through the body are hand-to-hand, hand-to-foot, or head-to-foot. Different pathways have been hypothesised to have different patterns of sequelae associated with them. For example, hand-to-hand pathways are associated with a greater risk of mortality, presumably because vital organs (e.g. heart) are likely to feature along that path. It is reasonable to assume that pathways from head-to-anywhere would be associated with higher levels of neuropsychological impairments because the brain is in the 
path. Unfortunately, the effects of pathways on sequelae have not been studied extensively [7].

$\mathrm{AC}$ is three times as dangerous to the body as DC; there are two primary reasons for this. Firstly, AC can cause tetanic spasms in muscles leading to repetitive contractions of those muscles $[1,6]$. For example, if an individual's hand comes into contact with $\mathrm{AC}$ via an exposed electrical wire, the muscles in the hand may contract and the individual is unable to let go of the wire (the 'no let-go' response), leading to increased duration of electrical contact. Secondly, cardiac and respiratory systems appear to be especially sensitive to $\mathrm{AC}$ and damage to those systems can lead to severe sequelae or death.

Following a serious electrical trauma, a victim's injured muscles around the contact point may become massively swollen subsequent to cell membrane damage, resulting in a rise in local extracellular pressures identified clinically in tissues as a compartment syndrome. Oxygen and blood supply to tissue trapped in the compartment syndrome muscles is diminished. With hypoxia, further metabolic compromise and tissue destruction may result.

Serious electrical injury can also produce disturbances in cardiac conduction, with possible refractory cardiac arrhythmias.

Overall, the severity of the consequences depends on the following parameters: $[1,7,8]$

1. The touch voltage: low-voltage $(<1,000$ volts $)$ or highvoltage ( $>1,000$ volts)

2. The type of current: DC or AC

3. The duration of current flow

4. The current path through the body e.g. hand to hand or hand to foot, and the presence of vital organs along the path

5. The humidity of the surroundings

6. Additional slash injury from the electrical arc as it passes from the source to an object

7. Additional thermal injury from the ignition of clothing or surroundings.

Pathogenesis and pathophysiology of neurological sequelae of electrical injuries

The pathophysiology of neurological sequelae of electrical injuries is still vague. The proposed explanations of the phenomenon include either direct mechanical or thermal damage to the nervous tissue, or indirect and possibly delayed effects as a result of complex hypothetical pathophysiological mechanisms. After a severe electrical trauma, diverse morphological changes in the central and peripheral nervous system have been noted. A characteristic and early event in CNS damage is microglial activation. Furthermore, neuron loss, neuronal chromatolysis and neuronophagia as well as infiltration of neutrophils and macrophages via the blood-brain barrier can occur [9].

The most common among hypothetical pathophysiological mechanisms for delayed neurological effects of electrical injuries are:
1. Vascular damage from electrical injury leading to vascular spasm, neuronal ischaemia, and ischaemia in the tissues supplied by the damaged vessels immediately after the trauma. Remaining chronic ischaemia after the initial injury, which slowly but steadily harms the tissue it supplies, and a chronic inflammatory reaction of vascular endothelial cells due to free radicals resulting from oxidative stress, have been hypothesised as causes of the delay in onset of symptoms $[10,11]$.

2. Pure electrical damage inducing electrostatic separation of tissues, and electroporation of cells. Electroporation is the process of opening the pores in the cell membranes using a pulse of electricity. The formation of extra pores in neurons may be responsible for cellular loss or functional deterioration immediately, or progressively, after electrical trauma [11].

3. Alteration of protein and/or DNA and especially the lipids found plentifully in myelin cells due to electrical current and the produced free radicals from oxidative stress, leading to demyelination [11].

4. According to Andrews and Reisner [10], the neurohumoural hypothesis is the most convincing to date in explaining both delayed and remote action: under influence of the electrical current, circulating substances are released, and are carried in the blood stream to act at a distance. Evidence has been presented suggesting that cortisol, which is released in trauma, augments hyperstimulation of glutamate receptors, which in turn augments the release of destructive free radicals [12]. Furthermore, one study has demonstrated that free radicals are extremely elevated in a lightning injury [13]. It is suggested that a complex interaction among electric current, glutamate, cortisol, free radicals and vessel walls may be responsible for the delayed and distant effects of electrical injuries on the CNS and the peripheral nervous system [10].

\section{Methods}

This review complies with the regulations of the Preferred Reporting Items for Systematic Reviews and Meta-Analyses (PRISMA) assertion [14].

The articles accepted for this review were case reports or case series or original research studies of patients where neurological or neurourological consequences were caused by electrical injuries (including lightning strikes) which were written in English. There was no restriction with regard to the year of publication.

All articles providing experimental or theoretical data or animal studies as well as reviews, editorials, commentaries or studies without a peer-review process were excluded. All studies with an ambivalent description of the process of the electrocution or the type of current were also excluded. Furthermore, articles on medical devices were excluded if their 


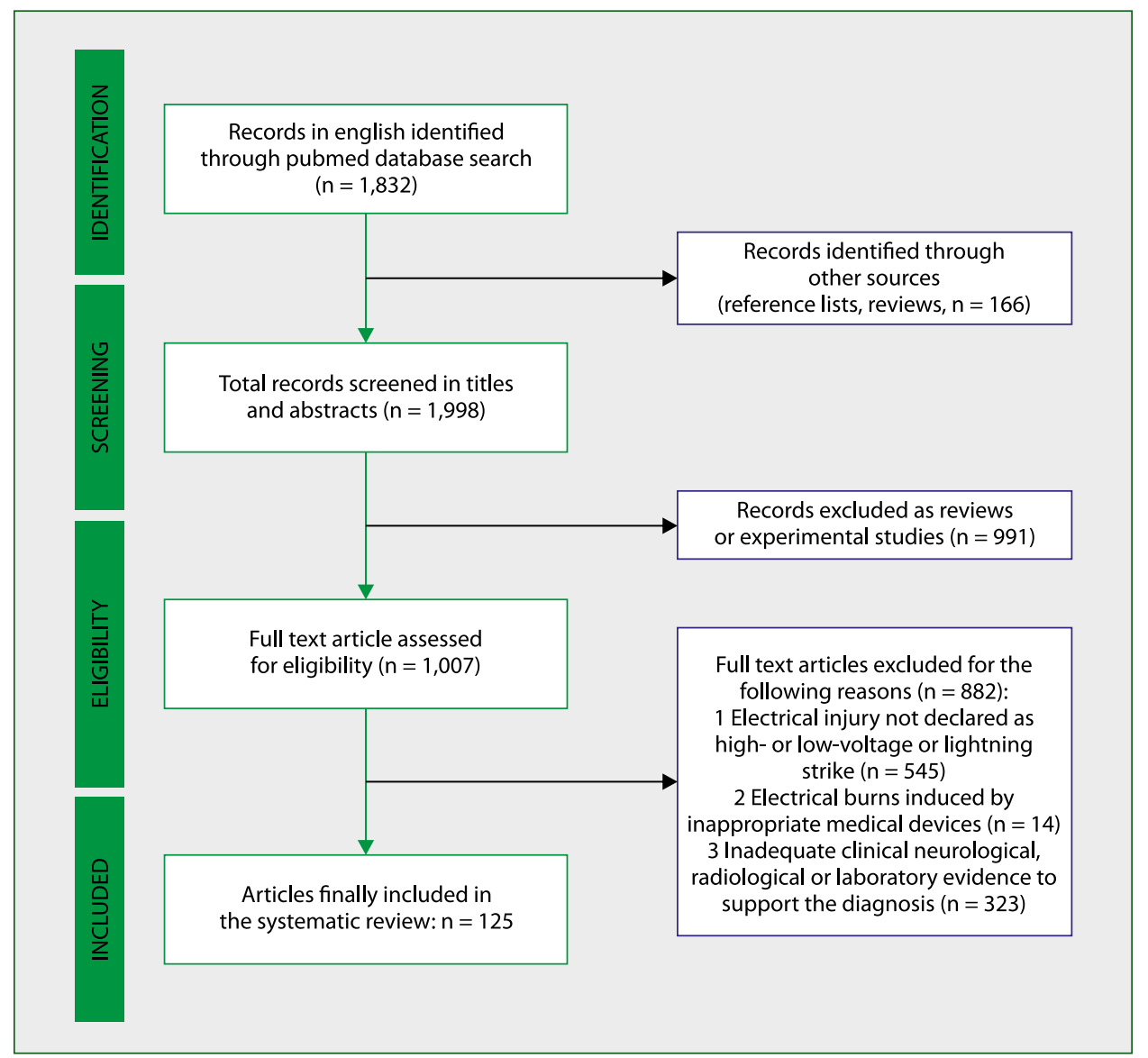

Figure 1. Literature search for the purposes of this review article

inaccurate application had caused electrical burns. Articles were also excluded if the clinical, laboratory or radiological evidence was not strong or clear enough to support the neurological diagnosis and the connection with the electric trauma.

We carried out a systematic literature search to identify relevant studies without restriction of the publication year using the Medline/PubMed database. Each article was discovered using combinations of the key words electrical injury or trauma or burn or electrocution, and neurological or urological or neurourological complications, neurogenic and bladder. The last literature query was conducted on $30 \mathrm{April}, 2020$.

In the first stage of assessment of all potentially relevant articles, the titles and abstracts were screened independently for eligibility by two authors (KGY and AIA). In the second stage, for those titles and abstracts which met the eligibility criteria, the full text was reviewed by the same two authors. Any disagreement was discussed and resolved between three authors (KGY, AIA and KK). The extracted data incorporated bibliographical data, demographic information regarding the patients, details of the current contact and the circumstances of the injury, while all neurological and neurourological consequences were independently recorded and revised by the same three authors.
This systematic search, as depicted in Figure 1, resulted in an initial number of 1,998 potentially relevant articles. After screening the title and abstract, 991 publications were excluded as reviews or experimental studies. A full-text eligibility analysis was performed for the remaining 1,007 articles. The full text articles that were excluded numbered 882 , and the decision for their exclusion was based on the following reasons: a precise description of the current type (i.e. high- or low-voltage or lightning) was lacking in 545 articles; electrical burns were induced by inappropriate application of medical devices in 14 articles; and clinical neurological, radiological or laboratory evidence for supporting the diagnosis was inadequate in 323 articles.

The remaining 125 publications fulfilled the eligibility criteria, and were included in this review. The eligible articles were published between 1977 and 2000.

Electrical injuries were caused by various electrical sources, including lightning, high-voltage power lines, or low-voltage power lines in occupational settings, indoors and outdoors.

Peripheral nervous system (PNS) entities were reported in 39 articles, central nervous system (CNS) complications in 94, autonomic nervous system (ANS) dysfunction in 15, and neurourological sequelae in 16 . 
The PubMed database was searched for English language clinical observational, retrospective, review and case studies, using the key words electrical injury, electrocution, complications, sequelae, neurological, urological, neurourological, neurogenic and bladder.

The broad spectrum of neurological and neurourological consequences of electrical trauma are identified and classified.

\section{Clinical course of neurological complications of electrical trauma}

Neurological sequelae of electrical injury can be divided into four categories [15]:

1. symptoms appear immediately after the injury and last only for hours or days (immediate and transient);

2. symptoms appear immediately after the injury and last for some weeks, months, years or forever (immediate and prolonged or permanent);

3. symptoms are not noticed at the time of the injury but appear later with progressive severity over time (delayed and progressive);

4. direct effects of the electrical injury induce other indirect secondary injuries (linked, secondary or indirect) [15].

The first and second categories are the most common responses of the body to injury. A paradigm of a transient and immediate sequel of electrical injury might be retrograde amnesia or loss of consciousness [5]. A prolonged immediate effect could be a brain haematoma or infarction.

The third and fourth categories are less typical, and add to the confusing nature of electrical injuries. Examples from the literature of the third category include amyotrophic lateral sclerosis, demyelination, thrombosis and dystonia [16]. Despite numerous reports of delayed, progressive sequelae, there has been little progress in the explanation of this phenomenon.

In the fourth category, indirect or linked coupled sequelae are entities that are indirectly related to the electrical injury incident. For example, due to the current entering and exiting the body, victims often fall, sometimes from great heights, and head injuries can occur. It is particularly challenging for the clinician to separate the effects of the electrical injury from the effects of these secondary injuries [5].

The same categorisation can be applied in cognitive, psychological and neurourological sequelae, whenever they are appropriately identified.

In non-fatal injuries, the exact symptomatology, its severity and duration are diverse and often unpredictable. No established relationship between injury or patient-related characteristics and subsequent neurological or neuropsychological injury has been proved apart from the suggestion of some studies that high-voltage injuries produce more frequent immediate sequelae, while low-voltage injuries tend to produce long-term ones [5, 17].

\section{Clinical presentation of neurological sequelae of electrical injury}

The following categories of neurological sequelae have been reported:

\section{Peripheral neuropathies: \\ 1. Mononeuropathies}

Mononeuropathy is the most frequent peripheral neuropathy following an electrical injury and is usually due to low-voltage electrical injury (which comprises $80 \%$ of peripheral neuropathies following an electrical injury). The cause may be electrical injury directly to the nerve, or compression neuropathy secondary to post-injury oedema [18].

Because electrical injuries are frequently occupational, the involvement of at least one hand in the task related to injury is usual. Consequently, median nerve compression and carpal tunnel syndrome are particularly possible [19]. Unfortunately, simultaneous immediate median and ulnar nerve palsy may also occur in the exposed upper limb while trineural (median, ulnar, and radial) injury has been also reported after a lowvoltage electrocution [20]. Additionally, unilateral ulnar and simultaneous external popliteal sciatic nerve mononeuropathy have been reported [21].

\section{Multiple bilateral mononeuropathies}

Multiple mononeuropathies after an electrical injury more often appear in cases with third- and fourth-degree burns. However, they have also been reported after low-voltage electrical injuries without serious cutaneous burns. Multiple nerve compressions with identified perineurial fibrosis at the time of decompression have been described simultaneously and bilaterally in the upper and lower extremities [18].

\section{Polyradiculopathy}

Polyradiculopathy is correlated with multiple entry points (10\% of peripheral neuropathies following an electrical injury) [15]. It may appear after a lightning [22] or high voltage [15] injury as a unilateral brachial plexus lesion and can even result in a severe form of a Guillain-Barre-like syndrome [23].

\section{Peripheral polyneuropathy}

Peripheral polyneuropathy can appear after a high-voltage injury (10\% of peripheral neuropathies following an electrical injury) [18] or lightning strike [24]. Furthermore, small fibre polyneuropathy has been reported either associated with high- or with low-voltage injury [25].

Overall, peripheral nerve disorders can complicate rehabilitation after an electrical injury. In a large retrospective study of 311 electric company workers who suffered electrical injuries, peripheral neuropathies seem to be the dominant neurological consequence of electrical trauma (permanent in $18.9 \%$ of the injured persons, comprising $90 \%$ of the neurological sequelae in this population) [21]. 


\section{Cranial nerve dysfunction:}

Unilateral [26] and bilateral [27] facial nerve paralysis have been described after low- and high-voltage electrical injury respectively.

Bilateral persistent sensorineural hearing loss has been also reported caused by lightning [28], high-voltage electrical injury [29] or low-voltage electrical injury [30]. Overall, the commonest acoustic insult after lightning injury is conductive hearing loss secondary to tympanic membrane rupture, and the most frequent vestibular symptom is transient vertigo [28]. Electrical current injuries predominantly cause pure sensorineural hearing loss and may significantly increase a patient's lifetime risk of tinnitus or vertigo [29].

Furthermore, ocular nerve lesions have been reported due to lightning [31] and high-voltage electrical injury [32] leading to usually reversible diplopia [32] or blindness [31].

Different signs and symptoms linked to impairment of function of the lower cranial nerves (mainly dysphagia and dysarthria) have been described in various combinations of $9^{\text {th }}, 10^{\text {th }}, 11^{\text {th }}$ and $12^{\text {th }}$ nerve involvement, resembling a usually transient bulbar palsy syndrome secondary to either a high-voltage electrical injury [33] or a lightning strike [34].

Finally, a unique case of trigeminal neuralgia following lightning injury has been reported [35].

\section{Central nervous system (CNS) complications:}

1. Myelopathy can occur in any spinal cord level $[36,37,38]$, especially after high-voltage electrical injury or lightning injury. Myelopathy after electrical injury is usually immediate. However, delayed myelopathy can also occur $[37,38]$. The typical pattern is that of an initial hypotonia between days 2 and 10 after injury, followed by ascending paralysis, which is usually paraplegia followed by quadriplegia [37]. Magnetic Resonance Imaging (MRI) can reveal the exact level of the damage with the change of the signal in diffusion tensor imaging analysis. The spinal cord shows local or widespread demyelination of white matter, oedema or infarction [36]. Recovery may be complete, partial or absent [38].

Additionally, lightning or electrical injury may lead to indirect spinal cord damage, such as spinal fractures due to fall, sometimes from great heights. It is particularly challenging for the clinician to separate the effects of the electrical injury alone from the effects of these secondary injuries. However, the presence of fractures and the history of fall due to electrocution support the hypothesis of secondary injury. According to a quite recent retrospective study of 832 patients with a traumatic spinal cord injury, less than $7 \%$ of them showed spinal cord fractures, mainly of the thoracic vertebrae due to fall secondary to electrocution [39]. Three case reports of thoracic spine compression fractures as a result of electrical shock from a conducted energy weapon (a taser) have been also published [40].

\section{Traumatic brain injury (TBI):}

TBI has superseded the previous term 'head injury' as it better encapsulates the significance of the 'brain' [41]. TBI is defined as: "An alteration in brain function, or other evidence of brain pathology, caused by an external force" [42]. Consequently, electrical brain injury can be considered as a form of TBI either as a direct effect of the electrical current to the brain or as an indirect effect secondary to an electrocution-induced fall.

Specific epidemiological evidence considering the proportion of electrical brain injury among the other causes of TBI does not exist, probably because most of these accidents are included in the more general category of 'falls' that are responsible for TBI events. Falls are now considered to be the most common cause of TBI, according to the most recent epidemiological studies [41, 43]. Depending on the specific mechanisms of insult, TBI can be divided into three types: closed head, penetrating, and explosive blast TBIs [44]. Electrical trauma can mainly induce the first and third types. Moderate and severe TBIs as well as electrical brain injuries are associated with neurological and functional impairments: coma, paresis, aphasia, seizures, headache, nausea, memory and behavioural abnormalities. Most of these occur immediately after TBI, while some of them can persist for months or years [44]. TBI in general, as well as electrical TBI, can lead to several pathological injuries, most of which can be identified on neuroimaging [45]: cerebral contusion [45], focal and diffuse patterns of axonal injury with cerebral oedema $[45,46]$, delayed brain atrophy [46], skull fracture [47], epidural haematoma [48], subdural haematoma [48], subarachnoid haemorrhage [49], intraparenchymal haemorrhage [50,51], and intraventricular haemorrhage [52]. In particular, the basal ganglia seem prone to electrical brain injury, especially in cases without skull fracture [50].

3. Ischaemia (stroke): One of the most devastating pathophysiological mechanisms induced by electrical injury is vasospasm. It can lead to any end-organ infarct and the brain is not spared the consequences. Nonetheless, cerebral infarction is only briefly mentioned compared to cerebral haemorrhage and traumatic injury due to either high- [53, 54] or low-voltage electrocution $[55,56]$.

4. Cerebellar syndromes: About 10 cases of cerebellar syndromes after electrocution have been reported to the best of our knowledge, some of them transient and some of them permanent with delayed cerebellar atrophy [57]. Cranial orifices are possible portals of entry to the body and specific access to the cerebellum [57]. Lightning is the most usual cause of a cerebellar infarction secondary to electrical injury [57]. However, cerebellar infarctions after a low-voltage [58] or a high-voltage electrical injury have also been reported [59], as well as cerebellar haemorrhage after a high-voltage injury [60]. 
5. Cerebral oedema: This has been reported not only as a part of a TBI pathology due to electrical injury, but also as the only consequence secondary to a high-voltage electrical burn to the scalp which can be reversible [61] or fatal [62].

6. Hydrocephalus: This has been described as a new-onset clinical syndrome with symptoms of elevated intracranial pressure and radiological evidence of ventricular dilatation. It usually requires shunt insertion [63].

7. Intracerebral venous thrombosis: This can occur secondary to a high-voltage electrical injury to the scalp even if the brain is out of the current's pathway $[64,65]$.

8. Epileptic seizures: Loss of consciousness, confusion, convulsive seizures, and poor recall immediately after a highvoltage injury are well known as immediate influences on the CNS. Convulsive seizures at the time of electrical shock, and epilepsy as a sequel of TBI caused by electrocution, are also well recognised [44, 66]. Nevertheless, epilepsy as a late-onset consequence of electrical trauma can also occur [67].

9. Loss of consciousness: This is very common after an electrical injury of any kind, and can be the result of brain injury, cardiac complications, epilepsy or autonomic dysfunction [8]. However, it can also appear as the only reported symptom in cases of low-voltage electrical injury [68] or lightning [69] in which the patient is unaware of the accident.

\section{Movement disorders}

a. Parkinsonism

Extrapyramidal rigidity or parkinsonian tremor have been sporadically reported secondary to high-voltage electrical injury [70]. Basal ganglion lesions were noted in the brain MRI of one reported patient [70].

b. Myoclonus

Myoclonus has been reported in more than 20 cases of mainly high-voltage electrical injury either immediately afterwards or as a delayed symptom, even decades later [71].

\section{c. Choreoathetosis}

This has been reported as a delayed consequence after high-voltage electrical injury accompanied by other extrapyramidal disorders (tremor, rigidity, myoclonus) $[70,71]$.

\section{d. Tremor}

This has been described as lingual tremor, probably due to a brainstem dysfunction, after a high-voltage electrical injury [72] and as a focal dystonic tremor in a limb affected by the electrical current after a low-voltage electrical injury [16].

\section{e. Dystonia}

Dystonia is a rare consequence of electrocution: only 10 cases of dystonia secondary to low-voltage electrical injury have been published [16]. They include lingual involvement (two cases) [73], upper limb involvement (five cases) [74], lower limb involvement (one case) [16], and torticollis (two cases) [75]. The pathophysiological mechanisms of electrocution-induced dystonia remain unknown, but it is mainly considered to be a form of trauma-induced movement disorder [16]. Post-traumatic dystonia occurs after both peripheral and central lesions. Direct damage to the nervous system, as well as a variety of delayed indirect mechanisms, including ephaptic transmission, aberrant neuronal sprouting, denervation supersensitivity, reorganisation of the spinal cord's synaptic connections, and oxidative reactions are some of the pathophysiological theories that have been put forward [16].

11. Amyotrophic lateral sclerosis (ALS): The prevalence of ALS in electricity-related occupations seems to be increased according to different epidemiological studies $[76,77]$, case series [78] and case reports [79]. History of electric shock has been listed as one of the main risk factors that may be associated with ALS in two recent metaanalyses $[80,81]$. It is suggested that ALS pathogenesis might be triggered by recurrent minor or more serious electrical injuries. Although the reported evidence until now is not always supportive of the connection of ALS to electrical injury [82], current data overall tends to support this hypothesis $[76,80,81]$.

\section{Autonomic nervous system (ANS) dysfunction:}

Three types of ANS disorders secondary to lightning or electrical injury can occur: complex regional pain syndrome (CRPS) or reflex sympathetic dystrophy (RSD), autonomic cardiovascular complications, and keraunoparalysis (KP).

Patients with CRPS present with unexplained diffuse pain (usually of an extremity), hyperpathia, allodynia, sweating, oedema and colour or temperature changes hours to weeks after a low-voltage electrical trauma [83]. Even years after the acute phase of electrical injury, the sympathetic skin response (SSR) remains impaired. This evidence suggests a prolonged ANS dysfunction in these patients and explains the derangement of bone metabolism in them [84]. Furthermore, it seems that SSR measurement predicts the occurrence of post-electrical injury autonomic dysfunction symptoms, and even bone loss in all electrical burn victims [84].

A variety of autonomic cardiovascular complications have been ascribed to lightning strike including severe orthostatic hypotension and postural tachycardia syndrome [85] and two cases indicative of hyperadrenergic dysautonomia with persistent sinus tachycardia and episodes of hypertension, sweating, and agitation [86].

Keraunoparalysis, also known as Charcot's paralysis, consists of transient limb paralysis (more commonly of the lower limbs), numbness, pallor, coolness and absent pulses of the affected limbs. It automatically reverses in a matter of few hours or days. The hypothesis explaining this phenomenon is 
adrenergic discharge and catecholamine release leading to temporary intense vasospasm of the spinal and peripheral arteries. Keraunoparalysis is always a diagnosis of exclusion while it is confirmed only when any other possible cause of paresis secondary to trauma has been investigated and rejected [87].

Pupil reactions can also become abnormal as a sign of ANS dysfunction. Fixed dilated pupils due to massive catecholamine release is one of the described consequences of high-voltage electrical injury [88] or lightning injury [89] as well as anisocoria due to Horner's Syndrome [90] after highvoltage electrical injury. Consequently, even the presence of lasting bilateral mydriasis in a comatose patient should not always be considered a decisive factor for non-escalation of treatment.

\section{Clinical presentation of neurourological sequelae of electrical injury}

The neurourological complications of electrical trauma can occur as a direct consequence of a neurological or muscle injury or as an indirect consequence of an insidious neurological dysfunction.

The main urological functions that can be affected secondary to an electrical injury are lower urinary tract function, erectile function, and renal function:

I. Urinary dysfunctions: Lower Urinary Tract Symptoms (LUTS) must be estimated in electrical trauma patients, and if present clinical and laboratory investigation (urodynamic and imaging studies) should follow [91].

a. Overactive bladder: This is the result of the dyssynergia between detrusor and detrusor sphincter combined with high detrusor pressure and can be responsible for lower or upper urinary tract infections, upper urinary tract dilatation, and even renal failure. Suprapontine cerebral lesions or cervical and thoracic myelopathy secondary to electrical injury can induce this syndrome [92].

b. Underactive bladder: This appears with urinary retention and voiding dysfunction and can also induce urological complications. Cerebral or spinal lesions between the pontine micturition centre in the brainstem and the sacral micturition centre in the sacral spinal cord are the usual causes. Underactive bladder is the most common sequel of myelopathy secondary to electrical injury [73].

\section{Erectile dysfunction}

a. Due to high-voltage injuries without recognised neurological injury (severe penile trauma, penile amputation) $[93,94]$

b. Due to spinal cord injury [94]:

Taking into consideration that the two neurological pathways which lead to an erection are: firstly reflex via tactile stimulus perception by the autonomic parasympathetic fibres of the $2^{\text {nd }}$ to $4^{\text {th }}$ sacral spinal cord segments, which results in vasodilation and opening of the arteriovenous shunts in the corpora cavernosa, and secondly psychogenic via autonomic sympathetic fibres at $11^{\text {th }}$ thoracic to $2^{\text {nd }}$ lumbar level and the hypogastric plexus, we can understand that a complete upper motor neuron injury above thoracic 11 level can result in the absence of psychogenic erections and the presence of only reflex erections, while men with a lower motor neuron injury affecting the sacral 2-4 level have only psychogenic erections and no reflex erections. There is, however, a considerable degree of variability of function in incomplete injuries. Myelopathy after high-voltage electrical injury or lightning injury can occur as a direct injury in any spinal cord level [36-38], and it can also occur secondary to indirect spinal cord damage such as spinal fractures due to fall, mainly of the thoracic vertebrae [39].

c. Due to traumatic rupture of the corpus cavernosum following a direct penile electrical trauma [95].

d. Due to autonomic dysfunction secondary to electrical injury [88].

III. Acute renal failure: This is an acute consequence of muscle distraction following electrical injury and myoglobinuria. Rigorous clinical and laboratory evaluation of the electrically traumatised patient must exclude or swiftly diagnose this life-threatening entity [96]. A rise in serum creatine phosphokinases (CK), rhabdomyolysis, myoglobinuria and acute renal failure are events during the early phase of admission more often in high-voltage injury patients than low-voltage [96]. High voltages, especially of the direct type, penetrate deep tissues and induce extended unexpected myonecrosis [97]. Consequently, patients in the high-voltage subgroup usually demand a statistically significant higher median total intravenous fluid administration over the first 24 hours after injury [98] with a goal of $1 \mathrm{~mL} / \mathrm{kg} / \mathrm{h}$ of urine output for adult patients.

These remarks reinforce the importance of assessing electrical injuries and obtaining a voltage injury profile to provide patient-specific care. Overall, serum myoglobin and CK levels reflect the severity of injury and may predict a more complex clinical course [99]. Specifically, renal electrical injury requiring haemofiltration is associated with a 12 -fold increased mortality risk [100].

\section{Closing remarks}

On admission to emergency departments after an electrical injury, physical and especially CNS examination intercurrently with stabilisation of cardiorespiratory status and wounds management must be prioritised.

Resuscitation attempts should be as intense as possible independently of pupil reactions, since these can be deteriorated simply by an ANS dysfunction. Immediately afterwards, main laboratory studies, and radiological evaluation should be 
performed. Exclusion of brain haemorrhage should be a priority. A head computed tomography $(\mathrm{CT})$ is warranted for any patient presenting with altered mental status, known trauma to the head, loss of consciousness, seizure or any focal neurological deficits. In addition to a head CT, these patients should be immobilised at the cervical spine, and imaging of the cervical spine may also be considered (although this may not be warranted in a patient with no focal neurological deficits, no changes in mental status, and no significant injury). The possibility of acute myelopathy should be evaluated as soon as possible for the purpose of avoiding any further permanent disability.

Evaluation of the peripheral sensory and motor functions, as well as hearing and vision, can be prosecuted concomitantly with further wounds management.

Possible neurourological sequelae, especially acute renal failure due to myoglobinuria, should be immediately excluded. Specifically, serum myoglobin and CK levels can reflect the severity of injury and predict a more complex clinical course.

\section{Conclusions}

Physical, neurological and neurourological consequences of electrical injuries occur in a high proportion of victims, and can seriously affect their permanent wellbeing. Early diagnosis and management of these disorders is of paramount importance for the avoidance of life-threatening complications and long-lasting disability.

Future research will be improved if case reports and studies were to describe their cases with a considerable degree of detail about the circumstances of the electrical injury, the type of the current, the time interval between the accident and the medical support provided, and whether there was access to a specialised burns unit.

Furthermore, because possible delayed neurological consequences of electrical injuries are poorly documented, we recommend conducting prospective studies that include an extensive follow-up period. Additionally, local epidemiological studies could improve workplace design for safety and help in educating industrial and domestic workers about potential hazardous situations.

The clear specification of data could be sufficient for the development of evidence-based guidelines on the diagnosis and therapeutic management of patients with neurological consequences of electrical injuries. Besides, this would be helpful for the purpose of better anatomical and functional classification of these disorders. and for the clarification of their pathophysiological mechanisms.

Conflict of interest: None.

Acknowledgement and financial support: None.

\section{References}

1. Shih JG, Shahrokhi S, Jeschke MG. Review of Adult Electrical Burn Injury Outcomes Worldwide: An Analysis of Low-Voltage vs High-Voltage
Electrical Injury. J Burn Care Res. 2017; 38(1): e293-e298, doi: 10.1097/BCR.0000000000000373, indexed in Pubmed: 27359191.

2. Ding $H$, Huang $M, L i ~ D$, et al. Epidemiology of electrical burns: a 10year retrospective analysis of 376 cases at a burn centre in South China. J Int Med Res. 2019 [Epub ahead of print]: 300060519891325, doi: 10.1177/0300060519891325, indexed in Pubmed: 31854209

3. Tashiro J, Burnweit CA. Swimming Pool Electrical Injuries: Steps Toward Prevention. Pediatr Emerg Care. 2019; 35(4): 261-264, doi: 10.1097/PEC.0000000000001019, indexed in Pubmed: 28072669.

4. Wesner ML, Hickie J. Long-term sequelae of electrical injury. Can Fam Physician. 2013; 59(9): 935-939, indexed in Pubmed: 24029506.

5. Hahn-Ketter AE, Whiteside DM, Pliskin N, et al. Long-term consequences of electrical injury: neuropsychological predictors of adjustment. Clin Neuropsychol. 2016; 30(2): 216-227, doi: 10.1080/13854046.2016.1155647, indexed in Pubmed: 26930500.

6. Stockly OR, Wolfe AE, Espinoza LF, et al. The impact of electrical injuries on long-term outcomes: A Burn Model System National Database study. Burns. 2020; 46(2): 352-359, doi: 10.1016/j.burns.2019.07.030, indexed in Pubmed: 31420267.

7. Friedstat J, Brown DA, Levi B. Chemical, Electrical, and Radiation Injuries. Clin Plast Surg. 2017; 44(3): 657-669, doi: 10.1016/j. cps.2017.02.021, indexed in Pubmed: 28576255.

8. Dechent D, Emonds T, Stunder D, et al. Direct current electrical injuries: A systematic review of case reports and case series. Burns. 2020; 46(2): 267-278, doi: 10.1016/j.burns.2018.11.020, indexed in Pubmed: 31208768.

9. Huynh W, Lam A, Vucic S, et al. Corticospinal tract dysfunction and development of amyotrophic lateral sclerosis following electrical injury. Muscle Nerve. 2010; 42(2): 288-292, doi: 10.1002/mus.21681, indexed in Pubmed: 20589889.

10. Andrews CJ, Reisner AD. Neurological and neuropsychological consequences of electrical and lightning shock: review and theories of causation. Neural Regen Res. 2017; 12(5): 677-686, doi: 10.4103/1673-5374.206636, indexed in Pubmed: 28616016.

11. Reisner AD. Possible mechanisms for delayed neurological damage in lightning and electrical injury. Brain Inj. 2013; 27(5): 565-569, doi: 10.3109/02699052.2013.766928, indexed in Pubmed: 23473007.

12. Reul JM, Nutt DJ. Glutamate and cortisol-a critical confluence in PTSD? J Psychopharmacol. 2008; 22(5): 469-472, doi: 10.1177/0269881108094617, indexed in Pubmed: 18701640.

13. Bailey DM, Bärtsch P, Cooper MA. Electron paramagnetic resonance spectroscopic evidence of increased free radical generation and selective damage to skeletal muscle following lightning injury. High Alt Med Biol. 2003; 4(3): 281-289, doi: 10.1089/152702903769192241, indexed in Pubmed: 14561234.

14. Moher D, Liberati A, Tetzlaff J, et al. PRISMA Group, PRISMA Group, PRISMA Group, PRISMA Group, PRISMA Group, PRISMA Group, PRISMA Group. Preferred reporting items for systematic reviews and meta-analyses: the PRISMA Statement. Open Med. 2009; 3(3): e123e130, indexed in Pubmed: 21603045.

15. Cherington M. Central Nervous System Complications of Lightning and Electrical Injuries. Seminars in Neurology. 2008; 15(03): 233-240, doi: 10.1055/s-2008-1041028.

16. Yiannopoulou KG, Avramidis T, Divari R, et al. Focal dystonia, tremor and myokymic discharges secondary to electrical injury. Neurol Int. 2009; 1(1): e2, doi: 10.4081/ni.2009.e2, indexed in Pubmed: 21577357.

17. Shih JG, Shahrokhi S, Jeschke MG. Review of Adult Electrical Burn Injury Outcomes Worldwide: An Analysis of Low-Voltage vs High-Voltage 
Electrical Injury. J Burn Care Res. 2017; 38(1): e293-e298, doi: 10.1097/BCR.0000000000000373, indexed in Pubmed: 27359191.

18. Tamam Y, Tamam C, Tamam B, et al. Peripheral neuropathy after burn injury. Eur Rev Med Pharmacol Sci. 2013; 17 Suppl 1: 107-111, indexed in Pubmed: 23436672.

19. Wong YS, Ong CT, Hsieh YY, et al. Carpal tunnel syndrome after an electrical injury: a case report and review of literature. J Occup Health. 2018; 60(4): 320-323, doi: 10.1539/joh.2017-0247-CS, indexed in Pubmed: 29899196.

20. Cahill KC, Tiong WHC, Conroy FJ. Trineural injury to the right hand after domestic electrocution. J Burn Care Res. 2014; 35(5): e353e356, doi: 10.1097/BCR.0000000000000024, indexed in Pubmed: 24270082.

21. Piotrowski A, Fillet AM, Perez P, et al. Outcome of occupational electrical injuries among French electric company workers: a retrospective report of 311 cases, 1996-2005. Burns. 2014; 40(3): 480-488, doi: 10.1016/j.burns.2013.08.008, indexed in Pubmed: 24028742.

22. Patnaik A, Mahapatra AK, Jha M. Pan-brachial plexus neuropraxia following lightning: A rare case report. Surg Neurol Int. 2015; 6(Suppl 2): S110-S112, doi: 10.4103/2152-7806.153650, indexed in Pubmed: 25883854.

23. Anderson ML, O'Riordan J. Guillain-Barre syndrome-like illness in association with electrical shock injury. BMJ Case Rep. 2013; 2013, doi: 10.1136/bcr-2013-201532, indexed in Pubmed: 24136915.

24. Anketell J, Wilson FC, McCann J. 'Thunder bolts and lightning': survival and neurorehabilitation following out of hospital cardiac arrest secondary to lightning strike. Brain Inj. 2018; 32(12): 1585-1587, doi: 10.1080/02699052.2018.1496479, indexed in Pubmed: 30182738.

25. Rådman L, Gunnarsson LG, Nilsagård Y, et al. Neurosensory findings among electricians with self-reported remaining symptoms after an electrical injury: A case series. Burns. 2016; 42(8): 1712-1720, doi: 10.1016/j.burns.2016.05.017, indexed in Pubmed: 27317339.

26. Reddy D, Earan S, Kuppusamy K. Electrical Injury Causing Facial Nerve Palsy in a Toddler. Indian Pediatrics. 2020; 57(1): 76-77, doi: 10.1007/s13312-020-1713-1.

27. Vasquez JC, Shusterman EM, Hansbrough JF. Bilateral facial nerve paralysis after high voltage electrical injury. J Burn Care Rehabil. 1999; 20(4): 307-308, doi: 10.1097/00004630-199907000-00006, indexed in Pubmed: 10425593.

28. Bozan N, Kiroglu AF, Ari M, et al. Tympanic Membrane Perforation Caused by Thunderbolt Strike. J Craniofac Surg. 2016; 27(8): e723e724, doi: 10.1097/SCS.0000000000003036, indexed in Pubmed: 28005796.

29. Choi DJ, Kim BG, Park IS, et al. Three cases of inner ear damage after electrical burns. Burns. 2010; 36(6): e83-e86, doi: 10.1016/j. burns.2009.10.015, indexed in Pubmed: 20036065.

30. Liew L, Morrison GAJ. Bilateral hearing loss following electrocution. J Laryngol Otol. 2006; 120(1): 65-66, doi: 10.1017/ S0022215105000514, indexed in Pubmed: 16359135.

31. Norman ME, Younge BR. Association of high-dose intravenous methylprednisolone with reversal of blindness from lightning in two patients. Ophthalmology. 1999; 106(4): 743-745, doi: 10.1016/ S0161-6420(99)90160-4, indexed in Pubmed: 10201596.

32. Baqain $E$, Haertsch P, Kennedy P. Complete recovery following a high voltage electrical injury associated with delayed onset of quadriplegia and multiple cranial nerves dysfunction. Burns. 2004; 30(6): 603-605, doi: 10.1016/j.burns.2004.01.024, indexed in Pubmed: 15302431.
33. Parvathy G, Shaji CV, Kabeer KA, et al. High-voltage electrocution causing bulbar dysfunction. J Neurosci Rural Pract. 2016; 7(3): 453-455, doi: 10.4103/0976-3147.181479, indexed in Pubmed: 27365968.

34. Desai BK, Fairclough R. A case of a speech impediment following a near lightning strike. Int J Emerg Med. 2011; 4: 60, doi: 10.1186/1865-1380-4-60, indexed in Pubmed: 21929820.

35. López Chiriboga AS, Cheshire WP. Trigeminal Neuralgia Following Lightning Injury. J Oral Facial Pain Headache. 2017; 31(4): e7-e9, doi: 10.11607/ofph.1871, indexed in Pubmed: 29073666.

36. Ohn SH, Kim DY, Shin JiC, et al. Analysis of high-voltage electrical spinal cord injury using diffusion tensor imaging. J Neurol. 2013; 260(11): 2876-2883, doi: 10.1007/s00415-013-7081-1, indexed in Pubmed: 24002417.

37. Sharma SR, Hussain M, Hibong H. Cervical Myelopathy after High-voltage Electrical Burn of the Head: Report of an Unusual Case. Ann Indian Acad Neurol. 2018; 21(1): 76-79, doi: 10.4103/aian. AIAN_376_17, indexed in Pubmed: 29720804.

38. Freeman $C B$, Goyal M, Bourque PR. MR imaging findings in delayed reversible myelopathy from lightning strike. AJNR Am J Neuroradiol. 2004; 25(5): 851-853, indexed in Pubmed: 15140734.

39. Thompson C, Mutch J, Parent S, et al. The changing demographics of traumatic spinal cord injury: An 11-year study of 831 patients. J Spinal Cord Med. 2015; 38(2): 214-223, doi: 10.1179/2045772314Y.0000000233, indexed in Pubmed: 25096709.

40. Tyagi AC, Gill A, Felton B. Thoracic Compression Fracture as a Result of Taser Discharge. Clin Pract Cases Emerg Med. 2017; 1(4): 319-322, doi: 10.5811/cpcem.2017.7.33508, indexed in Pubmed: 29849357.

41. Peeters W, van den Brande R, Polinder S, et al. Epidemiology of traumatic brain injury in Europe. Acta Neurochir (Wien). 2015; 157(10): 1683-1696, doi: 10.1007/s00701-015-2512-7, indexed in Pubmed: 26269030.

42. Menon DK, Schwab K, Wright DW, et al. Demographics and Clinical Assessment Working Group of the International and Interagency Initiative toward Common Data Elements for Research on Traumatic Brain Injury and Psychological Health. Position statement: definition of traumatic brain injury. Arch Phys Med Rehabil. 2010; 91(11): 1637-1640, doi: 10.1016/j.apmr.2010.05.017, indexed in Pubmed: 21044706.

43. Heydari F, Golban M, Majidinejad S. Traumatic Brain Injury in Older Adults Presenting to the Emergency Department: Epidemiology, Outcomes and Risk Factors Predicting the Prognosis. Adv J Emerg Med. 2020; 4(2): e19, doi: 10.22114/ajem.v0i0.170, indexed in Pubmed: 32322787.

44. Ng SiY, Lee AY. Traumatic Brain Injuries: Pathophysiology and Potential Therapeutic Targets. Front Cell Neurosci. 2019; 13: 528, doi: 10.3389/fncel.2019.00528, indexed in Pubmed: 31827423.

45. Grassner L, Bierschneider M, Strowitzki M, et al. Different sequelae of electrical brain injury - MRI patterns. Burns. 2017; 43(4): e7-ee10, doi: 10.1016/j.burns.2017.03.012, indexed in Pubmed: 28400149.

46. Isao T, Masaki F, Riko N, et al. Delayed brain atrophy after electrical injury. J Burn Care Rehabil. 2005; 26(5): 456-458, doi: 10.1097/01. bcr.0000176890.12785.70, indexed in Pubmed: 16151296.

47. Lewis MC, Lewis DE. Frontal Sinus TASER Dart Injury. J Emerg Med. 2016; 50(3): 490-492, doi: 10.1016/j.jemermed.2015.09.024, indexed in Pubmed: 26603364.

48. Steward L, Wagner AL, Neumann R, et al. Delayed Presentation of a Vertex Epidural Hematoma Following High-Voltage Electrical Injury to the Head. J Burn Care Res. 2019; 40(4): 517-519, doi: 10.1093/ jbcr/irz042, indexed in Pubmed: 30938441. 
49. Krisht KM, Chamoun R, Couldwell WT. Supraclinoid internal carotid artery-inferior petrosal sinus arteriovenous fistula after high-voltage electrical burn injury. J Clin Neurosci. 2013; 20(7): 1036-1038, doi: 10.1016/j.jocn.2012.10.007, indexed in Pubmed: 23618677.

50. Caksen H, Yuca SA, Demirtas I, et al. Right thalamic hemorrhage resulting from high-voltage electrical injury: a case report. Brain Dev. 2004; 26(2): 134-136, doi: 10.1016/S0387-7604(03)00099-8, indexed in Pubmed: 15036434.

51. Axayacalt GA, Alejandro CE, Marcos RA, et al. Brain hemorrhage after electrical burn injury: Case report and probable mechanism. Surg Neurol Int. 2016; 7(Suppl 28): S759-S762, doi: 10.4103/21527806.193728, indexed in Pubmed: 27904757.

52. Sprecher W, Wenz W, Haffner HT. Rupture of an intracranial aneurysm--unusual complication of an electric shock. Forensic Sci Int. 2001; 122(2-3): 85-88, doi: 10.1016/s0379-0738(01)00475-3, indexed in Pubmed: 11672960.

53. Kokatnur L, Rudrappa M. Acute Stroke due to Electrocution: Uncommon or Unrecognized? Case Rep Neurol Med. 2016; 2016: 9510863 , doi: 10.1155/2016/9510863, indexed in Pubmed: 28058122.

54. Singh Jain R, Kumar S, Suresh DT, et al. Acute vertebrobasilar ischemic stroke due to electric injury. Am J Emerg Med. 2015; 33(7): 992. e3-992.e6, doi: 10.1016/j.ajem.2014.12.068, indexed in Pubmed: 25684743.

55. R SK, G SK, L M. Electrocution Causing Acute Ischemic Stroke - A Rare Presentation. J Assoc Physicians India. 2020; 68(1): 60, indexed in Pubmed: 31979641.

56. Verma GC, Jain G, Wahid A, et al. Acute ischaemic stroke and acute myocardial infarction occurring together in domestic low-voltage (220240V) electrical injury: a rare complication. J Assoc Physicians India. 2014; 62 (7): 620-623, indexed in Pubmed: 25672040.

57. Aslan S, Yilmaz S, Karcioglu O. Lightning: an unusual cause of cerebellar infarction. Emerg Med J. 2004; 21(6): 750-751, doi: 10.1136/ emj.2002.003731, indexed in Pubmed: 15496717.

58. Yang L, Cui C, Ding $\mathrm{H}$, et al. Delayed cerebellar infarction after a slight electric injury. Am J Emerg Med. 2018; 36(12): 2337.e3-2337.e5, doi: 10.1016/j.ajem.2018.08.064, indexed in Pubmed: 30177265.

59. Fleury V, Kleinig TJ, Thompson PD, et al. Cardio-embolic cerebellar stroke secondary to mitral valve chordae rupture as a delayed complication of a high-voltage electrical injury. J Clin Neurosci. 2008; 15(2): 210-212, doi: 10.1016/j.jocn.2006.09.008, indexed in Pubmed: 18068986.

60. Nizhu LN, Hasan MdJ, Rabbani R. High-voltage electrocution-induced pulmonary injury and cerebellar hemorrhage with fractures in atlas. Trauma Case Rep. 2020; 25: 100267, doi: 10.1016/j. tcr.2019.100267, indexed in Pubmed: 31832534.

61. Chandrasekhar DP, Noone ML, Babu SP, et al. Magnetic resonance imaging findings in brain resulting from high-voltage electrical shock injury of the scalp. Indian J Radiol Imaging. 2018; 28(3): 312-314, doi: 10.4103/ijri.IJRI_368_17, indexed in Pubmed: 30319207.

62. Shetty BS, Kanchan T, Shetty M, et al. Fatal electrocution by a support metal wire. J Forensic Sci. 2010; 55(3): 830-831, doi: 10.1111/j.1556-4029.2010.01365.x, indexed in Pubmed: 20345779

63. Ackerman LL, Ryken TC, Kealey GP, et al. Onset of symptomatic hydrocephalus requiring emergency cerebrospinal fluid diversion following high-voltage electrical burn injury. J Neurosurg. 2010; 112(2): 394-398, doi: 10.3171/2009.7.JNS09578, indexed in Pubmed: 19681688.
64. Sure U, Kleihues P. Intracerebral venous thrombosis and hematoma secondary to high-voltage brain injury. J Trauma. 1997; 42(6): 1161-1164, doi: 10.1097/00005373-199706000-00032, indexed in Pubmed: 9210561.

65. Singh G, Kaif M, Deep A, et al. High-voltage electrical burn of the skull causing thrombosis of the superior sagittal sinus. J Clin Neurosci. 2011; 18(11): 1552-1554, doi: 10.1016/j.jocn.2011.02.038, indexed in Pubmed: 21865045.

66. Grell K, Meersohn A, Schüz J, et al. Risk of neurological diseases among survivors of electric shocks: a nationwide cohort study, Denmark, 1968-2008. Bioelectromagnetics. 2012; 33(6): 459-465, doi: 10.1002/bem.21705, indexed in Pubmed: 22278991.

67. Neugroschl C, Berrada S, Elosegi JA, et al. Imaging of epilepsy following electrical injury. JBR-BTR. 2013; 96(2): 81-83, doi: 10.5334/ jbr-btr.215, indexed in Pubmed: 23847827.

68. Navinan MR, Kandeepan T, Kulatunga A. A case of paroxysmal atrial fibrillation following low voltage electrocution. BMC Res Notes. 2013; 6: 384, doi: 10.1186/1756-0500-6-384, indexed in Pubmed: 24070318.

69. Grzesiek M, Ellmann C, Ditting T. Put Your Lights On: Electrocution As a Cause of an Unexplained Fall and Loss of Consciousness. Eur J Case Rep Intern Med. 2019; 6(5): 001084, doi: 10.12890/2019_001084, indexed in Pubmed: 31157182.

70. Glatstein M, Scolnik D, Mari E, et al. Levodopa treatment of late onset extrapyramidal movements in a child after high voltage electrocution. Am J Ther. 2013; 20(5): 554-557, doi: 10.1097/ MJT.0b013e3181f69ef3, indexed in Pubmed: 21326086.

71. Parashar A, Chittoria R, Nanda V. Extrapyramidal symptoms following electrical burns-a case report. Burns. 2004; 30(4): 402-404, doi: 10.1016/j.burns.2003.11.006, indexed in Pubmed: 15145203.

72. Lin K, Lin J, Piovesan EJ, et al. Tongue tremor in a patient with coma after electrical injury. Mov Disord. 2003; 18(7): 834-836, doi: 10.1002/mds.10433, indexed in Pubmed: 12815667.

73. Baskerville JR, McAninch SA. Focal lingual dystonia, urinary incontinence, and sensory deficits secondary to low voltage electrocution: case report and literature review. Emerg Med J. 2002; 19(4): 368371, doi: 10.1136/emj.19.4.368, indexed in Pubmed: 12101168.

74. Lim ECH, Seet RCS. Segmental dystonia following electrocution in childhood. Neurol Sci. 2007; 28(1): 38-41, doi: 10.1007/s10072007-0746-8, indexed in Pubmed: 17385094.

75. Boonkongchuen $P$, Lees $A$. Case of torticollis occurring following electrical injury. Mov Disord. 1996; 11(1): 109-110, doi: 10.1002/ mds.870110126, indexed in Pubmed: 8771083.

76. Peters S, Visser AE, D'Ovidio F, et al. Euro-MOTOR Consortium. Associations of Electric Shock and Extremely Low-Frequency Magnetic Field Exposure With the Risk of Amyotrophic Lateral Sclerosis. Am J Epidemiol. 2019; 188(4): 796-805, doi: 10.1093/aje/kwy287, indexed in Pubmed: 30649156.

77. Vergara X, Mezei G, Kheifets L. Case-control study of occupational exposure to electric shocks and magnetic fields and mortality from amyotrophic lateral sclerosis in the US, 1991-1999. J Expo Sci Environ Epidemiol. 2015; 25(1): 65-71, doi: 10.1038/jes.2014.39, indexed in Pubmed: 24917188.

78. Jafari H, Couratier P, Camu W. Motor neuron disease after electric injury. J Neurol Neurosurg Psychiatry. 2001; 71(2): 265-267, doi: 10.1136/jnnp.71.2.265, indexed in Pubmed: 11459909.

79. Huynh W, Lam A, Vucic S, et al. Corticospinal tract dysfunction and development of amyotrophic lateral sclerosis following electrical inju- 
ry. Muscle Nerve. 2010; 42(2): 288-292, doi: 10.1002/mus.21681, indexed in Pubmed: 20589889.

80. Gunnarsson LG, Bodin L. Amyotrophic Lateral Sclerosis and Occupational Exposures: A Systematic Literature Review and Meta-Analyses. Int J Environ Res Public Health. 2018; 15(11), doi: 10.3390/ ijerph15112371, indexed in Pubmed: 30373166.

81. Wang MD, Little J, Gomes J, et al. Identification of risk factors associated with onset and progression of amyotrophic lateral sclerosis using systematic review and meta-analysis. Neurotoxicology. 2017; 61: 101-130, doi: 10.1016/j.neuro.2016.06.015, indexed in Pubmed: 27377857.

82. Fischer H, Kheifets L, Huss A, et al. Occupational Exposure to Electric Shocks and Magnetic Fields and Amyotrophic Lateral Sclerosis in Sweden. Epidemiology. 2015; 26(6): 824-830, doi: 10.1097/ EDE.0000000000000365, indexed in Pubmed: 26414853.

83. Kara M, Yalcin S, Malas FU, et al. Ultrasound imaging for the upper limb nerves in CRPS: a patient with electrical injury. Pain Physician. 2014; 17(4): E556-E557, indexed in Pubmed: 25054408.

84. Roshanzamir S, Keshavarzi E. Sympathetic skin response impairment: A good predictor of bone loss in electrical burn victims. Burns. 2020; 46(2): 394-399, doi: 10.1016/j.burns.2019.07.034, indexed in Pubmed: 31848086.

85. Kanjwal K, Karabin B, Kanjwal Y, et al. Postural orthostatic tachycardia syndrome: a rare complication following electrical injury. Pacing Clin Electrophysiol. 2010; 33(7): e59-e61, doi: 10.1111/j.1540-8159.2009.02634.x, indexed in Pubmed: 20015131.

86. Naik SB, Murali Krishna RV. A Case of Keraunoparalysis: A Bolt from the Blue. Indian J Crit Care Med. 2018; 22(11): 804-805, doi: 10.4103/ijccm.IJCCM_325_18, indexed in Pubmed: 30598568.

87. Rahmani SH, Faridaalaee G, Jahangard S. Acute transient hemiparesis induced by lightning strike. Am J Emerg Med. 2015; 33(7): 984. e1-984.e3, doi: 10.1016/j.ajem.2014.12.031, indexed in Pubmed: 25650360.

88. Delgadillo D, Chapman S, Fahrenkopf M, et al. Acute-Onset Quadriplegia With Recovery After High-Voltage Electrical Injury. Annals of Plastic Surgery. 2017; 79(5): e33-e36, doi: 10.1097/ sap. 0000000000001151.

89. Rotariu EL, Manole MD. Cardiac Arrest Secondary to Lightning Strike: Case Report and Review of the Literature. Pediatr Emerg Care. 2020; 36(1): e18-e20, doi: 10.1097/PEC.0000000000001255, indexed in Pubmed: 28767532.
90. Schaefer NR, Yaxley JP, O'Donohue P, et al. Electrical burn causing a unique pattern of neurological injury. Plast Reconstr Surg Glob Open. 2015; 3(4): e378, doi: 10.1097/GOX.0000000000000344, indexed in Pubmed: 25973356.

91. Welk B, Schneider MP, Thavaseelan J, et al. Early urological care of patients with spinal cord injury. World J Urol. 2018; 36(10): 1537-1544, doi: 10.1007/s00345-018-2367-7, indexed in Pubmed: 29948046.

92. Djordjevic ML, Bizic M, Stojanovic B, et al. Outcomes and special techniques for treatment of penile amputation injury. Injury. 2019; 50 Suppl 5: S131-S136, doi: 10.1016/j.injury.2019.10.064, indexed in Pubmed: 31753295.

93. Welk B, Schneider MP, Thavaseelan J, et al. Early urological care of patients with spinal cord injury. World J Urol. 2018; 36(10): 1537-1544, doi: 10.1007/s00345-018-2367-7, indexed in Pubmed: 29948046.

94. Rivas JG, Dorrego JM, Hernández MM, et al. Traumatic rupture of the corpus cavernosum: surgical management and clinical outcomes. A 30 years review. Cent European J Urol. 2014; 67(1): 88-92, doi: 10.5173/ceju.2014.01.art20, indexed in Pubmed: 24982791.

95. Djordjevic ML, Bumbasirevic MZ, Krstic Z, et al. Severe penile injuries in children and adolescents: reconstruction modalities and outcomes. Urology. 2014; 83(2): 465-470, doi: 10.1016/j.urology.2013.10.015, indexed in Pubmed: 24275276.

96. Srivastava S, Kumari $\mathrm{H}$, Singh A, et al. Electrical burn injury: a comparison of outcomes of high voltage versus low voltage injury in an Indian scenario. Ann Burns Fire Disasters 2018;30. ; 31(3): 174-177.

97. Culnan DM, Farner K, Bitz GH, et al. Volume Resuscitation in Patients With High-Voltage Electrical Injuries. Ann Plast Surg. 2018; 80(3 Suppl 2): S113-S118, doi: 10.1097/SAP.0000000000001374, indexed in Pubmed: 29461290.

98. Boyd AN, Hartman BC, Sood R, et al. A voltage-based analysis of fluid delivery and outcomes in burn patients with electrical injuries over a 6-year period. Burns. 2019; 45(4): 869-875, doi: 10.1016/j. burns.2018.08.020, indexed in Pubmed: 30935702.

99. Gille J, Schmidt T, Dragu A, et al. Electrical injury - a dual center analysis of patient characteristics, therapeutic specifics and outcome predictors. Scand J Trauma Resusc Emerg Med. 2018; 26(1): 43, doi: 10.1186/s13049-018-0513-2, indexed in Pubmed: 29855384.

100. Saracoglu A, Kuzucuoglu T, Yakupoglu S, et al. Prognostic factors in electrical burns: a review of 101 patients. Burns. 2014; 40(4): 702-707, doi: 10.1016/j.burns.2013.08.023, indexed in Pubmed: 24054987. 